\title{
Platelet receptor gain-of-function single nucleotide polymorphisms in carotid and vertebral stenosis patients
}

\author{
Andrea Kopp Lugli • Martin M. Brown · Jan Steffel • \\ Linda Büchi · Dorothee Förnzler · Annabelle Dupont • \\ Pascale Gaussem • Marc Forestier · Juerg H. Beer
}

Published online: 20 April 2011

(C) Springer Science+Business Media, LLC 2011

\begin{abstract}
The role of platelet receptor gain-of-function single nucleotide polymorphisms (SNP) in cardiovascular disease is controversial. We hypothesised that certain SNPs may accelerate the development of carotid artery stenosis. The intronic PAR-1 receptor intervening sequence-14 A/T (IVSn-14 A/T) polymorphism and three additional platelet
\end{abstract}

This study was presented in part at the 77th Meeting of Hematology in Lausanne, May 2009 and published in abstract form in Swiss Medical Forum 2009 (Suppl 46, p. 19) and presented at the 75th Swiss National Meeting of Internal Medicine in Basel, Switzerland, May 2007 and published in abstract form in Swiss Med Forum 2007 (Suppl 35, p. 165).

A. Kopp Lugli · L. Büchi · M. Forestier · J. H. Beer $(\bowtie)$

Department of Medicine, Cantonal Hospital Baden, 5404 Baden, Switzerland

e-mail: hansjuerg.beer@ksb.ch

A. Kopp Lugli

Department of Anesthesia, University Hospital, Basel,

Switzerland

M. M. Brown

Stroke Research Group, University College of London Institute of Neurology, London, UK

J. Steffel

Department of Cardiology, University Hospital, Zurich,

Switzerland

D. Förnzler

Hoffmann-La Roche, Basel, Switzerland

A. Dupont · P. Gaussem

Université Paris Descartes, AP-HP, Hôpital Européen Georges

Pompidou, INSERM, Unité 765, Paris, France

J. H. Beer

Department of Medicine, University Hospital Berne, Bern,

Switzerland receptor polymorphisms, i.e. GPIa (807C/T), GPIb $\alpha$ (5T/C) and HPA-1a/HPA-1b (Pl (A1/A2)) of GPIIIa were studied. The interaction of SNPs with conventional risk factors including male gender, hypertension, high cholesterol, diabetes, advanced age and smoking were investigated. The hypothesis was tested in 114 well-characterised patients with symptomatic carotid or vertebral stenosis from the British CAVATAS population and compared the results with 97 unrelated controls. The allele frequency of the platelet gainof-function SNP was not significantly different in the CAVATAS population as compared to controls (PAR-1A/T $(P=0.13)$, GPIa $\underline{\mathrm{C}} / \mathrm{T}(P=0.25)$, GPIIIa HPA-1a/HPA- $\underline{1 \mathrm{~b}}$ $(\mathrm{PlA} 1 / \mathrm{A} 2)(P=0.66)$ and GPIb T/C $(P=0.20))$. In the subgroup of smokers, however, the prothrombotic GPIb $\alpha \mathrm{C}$ mutated allele was found in a significantly higher frequency in the patient as compared to the control group $(P=0.04)$. Contrary to the primary hypothesis, the PAR-1A/T SNP as well as the other SNPs tested were not over- or underrepresented in the CAVATAS population. However, a significantly increased prevalence of GPIb- $\alpha(5 \mathrm{C} / \mathrm{T})$ was found in the subgroup of smokers and may represent an important cofactor in this patient group of our hypothesis-generating study.

Keywords Single nucleotide polymorphisms . Carotid stenosis - Platelet glycoprotein receptors

\section{Introduction}

Platelet receptor polymorphisms that result in a "gainof-function" in platelet adhesion and/or aggregation due to increased receptor density or affinity and increased platelet activation may place carriers at increased risk of vascular events and accelerate atherogenesis. Indeed, platelet adhesion to dysfunctional endothelium and activation with subsequent degranulation are important elements of the 
formation and kinetics of atherosclerotic lesions [1], which may be accelerated by gain-of-function platelet polymorphisms. Several such mutations have been described, but their contribution to clinical events remains controversial [2-7].

On this basis, we hypothesised that platelet gainof-function polymorphisms may predispose carriers to an accelerated development of atherosclerosis, especially in combination with exogenous risk factors.

Thrombin is known to increase vascular smooth muscle cell (VSMC) proliferation and migration (i.e. crucial mechanisms of atherosclerosis and neointima formation), and PAR-1 is widely expressed in VSMC in human atheromas indicating a role of this receptor in atherogenesis [8-11]. Therefore, our primary hypothesis was that the intronic PAR-1 receptor intervening sequence-14 A/T (IVSn-14 A/T) polymorphism would enhance local thrombin growth factor effects and accelerate the development of atherosclerotic lesions. So far, the association of this mutation with clinical events has not been investigated [12].

Three additional gain-of-function platelet-receptor single nucleotide polymorphisms (SNPs) of GPIb $\alpha(5 \mathrm{~T} / \mathrm{C})$, GPIa $(807 \mathrm{C} / \mathrm{T})$ and GPIIIa (HPA-1a/HPA-1b (also called PlA1/A2)) served as secondary endpoints, which have been demonstrated to increase clinical events, likely due to their gain-of-function mechanisms $[4,12-15]$ in addition to their interaction with behavioural risk factors. The GPIb $\alpha$ (5T/C) SNP was of particular interest, since the A1 binding site of von Willebrand factor (vWF) may be activated to bind platelet GPIb $\alpha$ under high shear stress, as it occurs in stenotic atherosclerotic lesions [16-19]. So far, clinical studies investigating the implications of the GPIb $\alpha(5 \mathrm{~T} / \mathrm{C})$ polymorphism have yielded controversial results $[4-7,20]$. Of particular interest was the combination of these polymorphisms with smoking (an acquired risk factor) as earlier studies have reported a strong association of smoking and platelet SNP with clinical events [21, 22].

\section{Materials and methods}

\section{Study population}

In the carotid and vertebral artery transluminal angioplasty study (CAVATAS), 504 patients with high grade carotid stenosis were randomised for endovascular versus surgical treatment [23]. Patients from this international multicentre study provide a well-characterised model population with a clearly defined carotid stenosis, in which gain-of-function polymorphisms could be correlated to the human situation of advanced atherosclerosis. After obtaining written informed consent, blood samples were taken from 114
CAVATAS patients from the British cohort in London and Sheffield [23]. The CAVATAS trial enrolled patients with carotid stenosis suitable for both carotid endarterectomy and endovascular treatment. Exclusion criteria included patients thought to be unsuitable for surgery because of medical or surgical risk factors (e.g., recent myocardial infarction, poorly controlled hypertension or diabetes mellitus, renal disease, respiratory failure, inaccessible carotid stenosis, or severe cervical spondylosis). Patients were also excluded if they were unable to give informed consent, or if they had a disabling stroke with no useful recovery of function within the region supplied by the treatable artery. There was no age limit. The available partners of the patients served as unrelated controls (97 samples). All controls had a negative history for myocardial infarction, angina, claudication, heart failure, stroke/ transient ischemic attack. The study was approved by the local internal review board (IRB).

While designing this hypothesis generating study we were careful to follow the standards of genetic association studies in stroke proposed by Dichgans and Markus [24]. To assess and compare the allelic frequency of platelet receptor SNP in an additional large representative control sample of a healthy Caucasian population, blood from 979 healthy Swiss blood donors was analysed.

\section{Detection of polymorphisms}

The polymorphisms were determined by the kinetic thermocycling method (KTC) $[25,26]$. The single nucleotide polymorphisms (SNP) for GPIa C807T and GPIIIa HPA$1 \mathrm{a} / \mathrm{HPA}-1 \mathrm{~b}$ were determined by the polymerase chain reaction and melting point analysis with fluorescent hybridisation probes by using the fluorescence energy transfer principle (LightCycler System, Roche, Basel, Switzerland).

\section{Statistical analysis}

We hypothesised that CAVATAS patients with carotid stenosis have a higher frequency of the prothrombotic AA (or lower TT)-SNP of PAR-1 (primary endpoint). As secondary endpoints, the association of the other three SNPs with carotid stenosis and their interaction with smoking were evaluated in an exploratory manner.

In our previous study [21] a relative risk of about 3.3 for patients with myocardial infarction who carry the collagen GPIa/IIa polymorphism (prevalence in the general population 5\%) has been found. Coronary restenoses appear to occur in the presence of the GP IIb/IIIa polymorphism (prevalence 20\%) at an odds ratio of 1.5-3 [27]. As for the Kozak polymorphism (GP1b) (allele frequency $8-17 \%$ in the general population) a conservative estimate may be in 
the range of a RR of 2-3. On the basis of these previous studies, expected restenosis rates [21, 27] and allele frequencies in a total of 200 (GP IIIa and GPIa) or 250 (GPIb) patients respectively will achieve a power of $80 \%$ ( $\alpha$ twosided 0.05).

Differences in SNP frequencies were assessed using Fisher's exact test. Additionally, a multiple logistic regression model with forward selection was fitted with the four SNPs and was adjusted for other confounding risk factors including male gender, hypertension, high cholesterol, diabetes, advanced age and smoking (only subjects with complete data for gender, hypertension, cholesterol, diabetes, age and smoking were included in this analysis). A significance level of 0.1 was used for the forward selection. For all other tests, a significance level of 0.05 was used. Statistical analyses were conducted using SAS System 9.1 (SAS Institute, Cary, NC, USA). The study was planned and conducted according the previously proposed standard criteria [24].

\section{Results}

Baseline characteristics and distribution of cardiovascular risk factors are summarised in Table 1. As expected, the prevalence of the cardiovascular risk factors: male gender $(P=0.006)$, hypertension $(P<0.0001)$, high cholesterol $(P=0.004)$, advanced age $(P<0.0001)$ and smoking $(P=0.014)$ were higher in the patient group as compared to controls.

The results of the distribution of the individual point mutations are summarised in Table 2. The allele frequencies of the PAR-1 SNP were similar among the patient and control groups (Fisher's exact test, $P=0.13$ ). Likewise, no significant difference was observed between the two groups with respect to GPIa $(P=0.25)$, GPIIIa $(P=0.66)$ and the GPIb $\alpha$ SNP (Fisher's exact test, $P=0.20$ ).

The multiple logistic regression model with forward selection included the factors hypertension $(P<0.0001)$, age $(P<0.0001)$, sex $(P=0.006)$, cholesterol $(P=$ $0.004)$ and smoking $(P=0.014)$. The odds ratio estimators were 4.89 (95\% CI 2.17-11.58) for hypertension, 1.14 (1.08-1.20) for age, 4.54 (2.06-10.64) for male gender, 4.24 (1.87-10.22) for cholesterol, 2.58 (0.96-7.34) for smokers versus non-smokers, and $0.35(0.10-1.13)$ for ex-smokers versus non-smokers. For example, an individual with hypertension has 4.89 times higher odds of being in the patient group than an individual without; likewise, or an individual who is 1 year older has 1.14 times higher odds to be in the patient group.

When patients were separated according to smoking status (i.e. non-smokers, ex-smokers and current smokers), the GPIb $\alpha$ mutation was overrepresented in the subgroup of
Table 1 Baseline characteristics and distribution of cardiovascular risk factors in CAVATAS patients and controls

\begin{tabular}{|c|c|c|c|}
\hline & Patients $(n=114)$ & Controls $(n=97)$ & $P$-values \\
\hline \multicolumn{4}{|l|}{ Gender } \\
\hline Male & $73(64.0 \%)$ & $40(41.2 \%)$ & \multirow[t]{3}{*}{0.006} \\
\hline Female & $33(29.0 \%)$ & $56(57.7 \%)$ & \\
\hline $\mathrm{n} / \mathrm{a}$ & $8(7.0 \%)$ & $1(1.0 \%)$ & \\
\hline \multicolumn{4}{|l|}{ Age } \\
\hline Mean & 71.5 & 63.3 & \multirow[t]{2}{*}{$<0.0001$} \\
\hline $\mathrm{n} / \mathrm{a}$ & 8 & 1 & \\
\hline \multicolumn{4}{|l|}{ Smoking } \\
\hline Current & $25(21.9 \%)$ & $17(17.5 \%)$ & \multirow[t]{4}{*}{0.014} \\
\hline Never & $73(64.0 \%)$ & $53(54.6 \%)$ & \\
\hline Ex-smoker & $8(7.0 \%)$ & $20(20.6 \%)$ & \\
\hline $\mathrm{n} / \mathrm{a}$ & $8(7.0 \%)$ & $7(7.2 \%)$ & \\
\hline \multicolumn{4}{|l|}{ Hypertension } \\
\hline Yes & $81(71.1 \%)$ & $39(40.2 \%)$ & \multirow[t]{3}{*}{$<0.0001$} \\
\hline No & $21(18.4 \%)$ & $52(53.6 \%)$ & \\
\hline $\mathrm{n} / \mathrm{a}$ & $12(10.5 \%)$ & $6(6.2 \%)$ & \\
\hline \multicolumn{4}{|l|}{ Diabetes } \\
\hline Yes & $11(9.7 \%)$ & $12(12.4 \%)$ & \multirow[t]{3}{*}{$\mathrm{n} / \mathrm{s}$} \\
\hline No & $89(78.1 \%)$ & $79(81.4 \%)$ & \\
\hline $\mathrm{n} / \mathrm{a}$ & $14(12.3 \%)$ & $6(6.2 \%)$ & \\
\hline \multicolumn{4}{|c|}{ High cholesterol } \\
\hline Yes & $68(59.7 \%)$ & $38(39.2 \%)$ & \multirow[t]{3}{*}{0.004} \\
\hline No & $28(24.6 \%)$ & $49(50.5 \%)$ & \\
\hline $\mathrm{n} / \mathrm{a}$ & $18(15.8 \%)$ & $10(10.3 \%)$ & \\
\hline
\end{tabular}

$n / a$ Not available, $n / s$ not significant

current smokers $(P=0.044$, Table 3$)$. In this group, the GPIb $\alpha$ mutation was included in the multiple logistic regression model with forward selection. The odds ratio estimators were 11.83 (95\% CI 1.30-231.65) for the GPIb $\alpha$ mutation, 4.59 (0.90-28.47) for dyslipidaemia, and 1.17 (1.05-1.35) for advanced age. Hence, an individual with the prothrombotic GPIb $\alpha(5 \mathrm{C})$ allele is at 11.8 times higher odds to be in the patient group than an individual without this allele (in the subgroup of smokers). Analyses testing interaction between SNPs and the smoking status (including current smokers, ex-smokers and non-smokers) did not reveal any statistically significant result (Tables 4,5 ).

According to previous published guidelines [24], we also tested if the marker genotypes were in HardyWeinberg equilibrium in CAVATAS patients and controls. In the CAVATAS group only PAR-1 Sn-14A/T was significant $(P=0.04)$, and in the control group only platelet GPlb $\alpha$ were significant $(P=0.04)$. Upon adjustment of the $P$-values for multiple statistical testing by Bonferroni correction, no $P$-value remains significant. Therefore, we may state that the marker genotypes are within a HardyWeinberg equilibrium $[24,28]$. 
Table 2 Summary of the distribution of the four polymorphisms in the CAVATAS patient cohort and controls

\begin{tabular}{|c|c|c|c|}
\hline & CAVATAS patients & Controls & $P$-value \\
\hline \multicolumn{4}{|l|}{ PAR-1 Sn-14트 } \\
\hline AA & $83(72.8 \%)$ & $68(70.1 \%)$ & \\
\hline AT & $25(21.9 \%)$ & $28(28.9 \%)$ & \\
\hline TT & $6(5.3 \%)$ & $1(1.0 \%)$ & \\
\hline Total number & 114 & 97 & 0.13 \\
\hline Odds ratio: 0.19 & $95 \%$ CI $0.02-1.59$ & & \\
\hline \multicolumn{4}{|c|}{ Platelet GpIb- $\alpha$ (5T/C्) } \\
\hline $\mathrm{CC}$ & $0(0.0 \%)$ & $0(0.0 \%)$ & \\
\hline $\mathrm{CT}$ & $23(20.2 \%)$ & $27(27.8 \%)$ & \\
\hline TT & $91(79.8 \%)$ & $70(72.2 \%)$ & \\
\hline Total number & 114 & 97 & 0.20 \\
\hline Odds ratio: 0.65 & $95 \%$ CI $0.35-1.24$ & & \\
\hline \multicolumn{4}{|c|}{ Platelet GpIa $807 \underline{\mathrm{C}} / \mathrm{T}$} \\
\hline $\mathrm{CC}$ & $43(37.7 \%)$ & $43(44.3 \%)$ & \\
\hline $\mathrm{CT}$ & $57(50.0 \%)$ & $36(37.1 \%)$ & \\
\hline TT & $14(12.3 \%)$ & $18(18.6 \%)$ & \\
\hline Total number & 114 & 97 & 0.25 \\
\hline Odds ratio: 1.63 & $95 \%$ CI $0.76-3.47$ & & \\
\hline \multicolumn{4}{|c|}{ Platelet GpIIIa (HPA-1a/HPA-1ㅁ; PI A $1 \underline{\mathrm{A}_{2}}$ ) } \\
\hline PI A2/A2 & $4(3.5 \%)$ & $3(3.1 \%)$ & \\
\hline PI A1/A2 & $36(31.6 \%)$ & $28(28.9 \%)$ & \\
\hline PI A1/A1 & $74(64.9 \%)$ & $66(68.0 \%)$ & \\
\hline Total number & 114 & 97 & 0.66 \\
\hline Odds ratio: 1.15 & $95 \%$ CI $0.65-2.04$ & & \\
\hline
\end{tabular}

The data collectively show no difference between the patients with carotid stenosis and the British controls. The underlined allele represents "the risk allel"

The calculated $P$-values are for risk allele versus no risk allele (e.g. in $\mathrm{A})$ : A is the risk allele therefore, AA and AT are tested versus TT

The overall frequency of the platelet receptor point mutations in the CAVATAS population and the respective controls was similar to a large representative control cohort of healthy Swiss blood donors (data not shown) suggesting that ethnicity did not play a role in these analyses.

\section{Discussion}

Contrary to our primary hypothesis, the PAR-1 (IVSn-14) SNP was not associated with symptomatic carotid stenosis. Furthermore, the three other "prothrombotic" platelet receptor SNPs were not overexpressed in patients. However, a significantly increased prevalence of GPIb- $\alpha(5 \mathrm{C} / \mathrm{T})$ was found in the subgroup of smokers, a typical exogenous atherogenic risk factor.

The study of gain-of-function polymorphisms is justified as they potentially increase the carrier's risk of atherosclerosis and/or vascular events. Indeed, platelet adhesion
Table 3 Distribution of the four polymorphisms in the subgroup of smokers

\begin{tabular}{llll}
\hline & CAVATAS patients & Controls & $P$-value \\
\hline PAR-1 Sn-14A/T & & & \\
AA & $16(66.7 \%)$ & $10(62.5 \%)$ & \\
AT & $7(29.2 \%)$ & $6(37.5 \%)$ & \\
TT & $1(4.2 \%)$ & $0(0 \%)$ & \\
Total number & 24 & 16 & $\mathrm{n} / \mathrm{s}$ \\
Platelet GpIb- $\alpha(5 \mathrm{~T} / \mathrm{C})$ & & \\
CC & $0(0.0 \%)$ & $0(0.0 \%)$ & \\
CT & $6(25.0 \%)$ & $2(12.5 \%)$ & \\
TT & $18(75.0 \%)$ & $14(87.5 \%)$ & \\
Total number & 24 & 16 & \\
Platelet GpIa 807 C/T & $5(20.8 \%)$ & $6(37.5 \%)$ & \\
CC & $16(66.7 \%)$ & $8(50 \%)$ & \\
CT & $3(12.5 \%)$ & $2(12.5 \%)$ & \\
TT & 24 & 16 & $\mathrm{n} / \mathrm{s}$ \\
Total number & & \\
Platelet GpIIIa (HPA-1a/HPA-1b; PI A $\left./ \underline{\mathrm{A}_{2}}\right)$ & & \\
PI A2/A2 & $0(0.0 \%)$ & $16(6.3 \%)$ & \\
PI A1/A2 & $7(29.2 \%)$ & $6(37.5 \%)$ & \\
PI A1/A1 & $17(70.8 \%)$ & $9(56.3 \%)$ & \\
Total number & 24 & 16 & \\
\hline
\end{tabular}

The data show an increased prevalence of the GpIb $\alpha \mathrm{C}$ allele in the CAVATAS patients as compared to the controls. The underlined allel represents "the risk allele"

$n / s$ Not significant

to dysfunctional endothelium and activation with subsequent degranulation are important elements of atherosclerotic lesion formation [1]. Polymorphism in the Kozak sequence of GpIb $\alpha$ is a major determinant of mRNA translation and, thus, the amount of GPIb present on the platelet surface, which is increased by the presence of the $\mathrm{C}$ allele at the -5 position $[4,29]$. This receptor and its interaction with vWF is of particular interest, because it is functional at the high shear rates found in arterial stenosis. Its inhibition results in reduced generation of platelet derived microparticles, thrombin generation and procoagulant activity at high shear forces [17, 18]. Furthermore, in vitro studies have shown that platelet membrane glycoprotein polymorphisms (including the Kozak sequence) influence experimental thrombus formation at typical shear rates [30]. So far, clinical studies investigating the implications of the GPIb $\alpha$ (5T/C) polymorphism have yielded controversial results. In 219 cases of first-ever ischemic stroke, presence of the $\mathrm{C}$ allele (as evidenced by an increased frequency of the T/C genotype) was overrepresented in the stroke group as compared to healthy controls even after adjusting for conventional risk factors [4]. In a study of 1000 patients with angiographically confirmed coronary artery disease, the GPIb $\alpha$ (5C) allele represented a 
Table 4 Distribution of the four polymorphisms in the subgroup of ex-smokers

\begin{tabular}{llll}
\hline & CAVATAS patients & Controls & $P$-value \\
\hline PAR-1 Sn-14A/T & & & \\
AA & $7(87.5 \%)$ & $13(72.2 \%)$ & \\
AT & $1(12.5 \%)$ & $5(27.8 \%)$ & \\
TT & $0(0.0 \%)$ & $0(0.0 \%)$ & \\
Total number & 8 & 18 & $\mathrm{n} / \mathrm{s}$ \\
Platelet GpIb- $\alpha(5 \mathrm{~T} / \mathrm{C})$ & & \\
CC & $0(0.0 \%)$ & $0(0.0 \%)$ & \\
CT & $1(12.5 \%)$ & $6(33.3 \%)$ & \\
TT & $7(87.5 \%)$ & $12(66.6 \%)$ & \\
Total number & 8 & 18 & $\mathrm{n} / \mathrm{s}$ \\
Platelet GpIa 807 C/T & & \\
CC & $5(62.5 \%)$ & $10(55.6 \%)$ & \\
CT & $3(37.5 \%)$ & $4(22.2 \%)$ & \\
TT & $0(0.0 \%)$ & $4(22.2 \%)$ & \\
Total number & 8 & 18 & $\mathrm{n} / \mathrm{s}$ \\
Platelet GpIIIa $\left(\mathrm{HPA}-1 \mathrm{a} / \mathrm{HPA}-1 \mathrm{~b} ;\right.$ PI $\left.\mathrm{A}_{1} / \underline{\mathrm{A}_{2}}\right)$ & \\
PI A2/A2 & $1(12.5 \%)$ & $1(5.6 \%)$ & \\
PI A1/A2 & $2(25.0 \%)$ & $5(27.8 \%)$ & \\
PI A1/A1 & $5(62.5 \%)$ & $12(66.7 \%)$ & \\
Total number & 8 & 18 & $\mathrm{n} / \mathrm{s}$ \\
\hline
\end{tabular}

The underlined allel represents "the risk allele"

$n / s$ Not significant

risk factor for thrombotic events [5]. Similarly, in a multicentre case-control study, homozygous $\mathrm{C} / \mathrm{C}$ genotype carriers had a 3.5-fold increased risk for ischaemic cerebrovascular events as compared to $\mathrm{T} / \mathrm{T}$ or $\mathrm{T} / \mathrm{C}$ genotype carriers together (independent of atherosclerotic risk factors), indicating a role of this allele in arterial thrombosis [6]. On the other hand, young women with the $\mathrm{C}$ allele of the GPIb $\alpha$ polymorphism do not appear to be at increased risk of myocardial infarction or non-fatal stroke, even in the subgroup of smokers [7]. The discrepancies between these studies may be accounted for by different patient selection criteria and studied outcomes, population size, age and other factors. A recent meta-analysis indicated a strong association of the $-5 \mathrm{~T} / \mathrm{C}$ polymorphism with the risk of ischaemic stroke. However, the direction of association was highly variable, suggesting that despite the presence of an association signal the true causative locus is perhaps not the Kozak $-5 \mathrm{~T} / \mathrm{C}$ sequence itself but rather a gene region nearby [20].

The interaction of the polymorphisms in smokers was of particular interest, as we have previously demonstrated the association of two silent and linked polymorphisms (807C/ $\mathrm{T}$ and $873 \mathrm{G} / \mathrm{A}$ ) within the GPIa gene with the risk of myocardial infarction, which was strongest in the subgroup
Table 5 Distribution of the four polymorphisms in the subgroup of non-smokers

\begin{tabular}{lccc}
\hline & CAVATAS patients & Controls & $P$-value \\
\hline PAR-1 Sn-14A/T & & & \\
AA & $43(71.7 \%)$ & $36(69.2 \%)$ & \\
AT & $12(20.0 \%)$ & $15(28.9 \%)$ & \\
TT & $5(8.3 \%)$ & $1(1.9 \%)$ & \\
Total number & 60 & 52 & $\mathrm{n} / \mathrm{s}$ \\
Platelet GpIb- $\alpha(5 T / C)$ & & \\
CC & $0(0.0 \%)$ & $0(0.0 \%)$ & \\
CT & $11(18.3 \%)$ & $16(30.7 \%)$ & \\
TT & $49(81.7 \%)$ & $36(69.2 \%)$ & \\
Total number & 60 & 52 & $\mathrm{n} / \mathrm{s}$ \\
Platelet GpIa 807 C/T & & \\
CC & $26(43.3 \%)$ & $24(46.2 \%)$ & \\
CT & $25(41.7 \%)$ & $18(34.6 \%)$ & \\
TT & $9(15.0 \%)$ & $10(19.2 \%)$ & \\
Total number & 60 & 52 & $\mathrm{n} / \mathrm{s}$ \\
Platelet GpIIIa (HPA-1a/HPA-1b; PI A $\left./ \mathrm{A}_{2}\right)$ & \\
PI A2/A2 & $2(3.3 \%)$ & $14(1.9 \%)$ & \\
PI A1/A2 & $22(36.7 \%)$ & $37(71.2 \%)$ & \\
PI A1/A1 & $36(60.0 \%)$ & 52 & $\mathrm{n} / \mathrm{s}$ \\
Total number & 60 & & \\
\hline
\end{tabular}

The underlined allel represents "the risk allele" $n / s$ Not significant

of smokers [21]. In the same line, polymorphisms of the GPIIb/IIIa gene and smoking were shown to affect the risk of stroke (while the SNP in itself did not) [22]. Our observation of an increased frequency of the GPIb $\alpha-5 \mathrm{C}$ allele in smokers with established atherosclerosis is in agreement with and extends these previous findings, not only for the ischemic events but also for the preceding development of arterial stenoses. In our present study, the odds estimator of the effect of the GPIb $\alpha$ (5C) allele in this subgroup was 11.83 while it was only 4.59 for hypercholesterolemia, implying an even more important effect of the $\mathrm{GPIb} \alpha$ mutation as compared to this well-established atherogenic risk factor. However, given the small subgroup in which this finding was detected $(\alpha=0.05, \beta=0.775)$ the significant $P$-value should be used as hypothesis-generating finding for further analysis in a larger population with a matched pair control group.

An accelerated development of atherosclerotic lesions in patients carrying the $-5 \mathrm{C}$ allele may potentially occur through an altered interaction of the GPIb-V-IX complex with vWF and, subsequently, an enhanced interaction of vWF with the (sub-) endothelium as proposed in Fig. 1. As the A1 binding site of vWF may be activated to bind platelet GPIb $\alpha$ under high shear stress by anchoring of the 


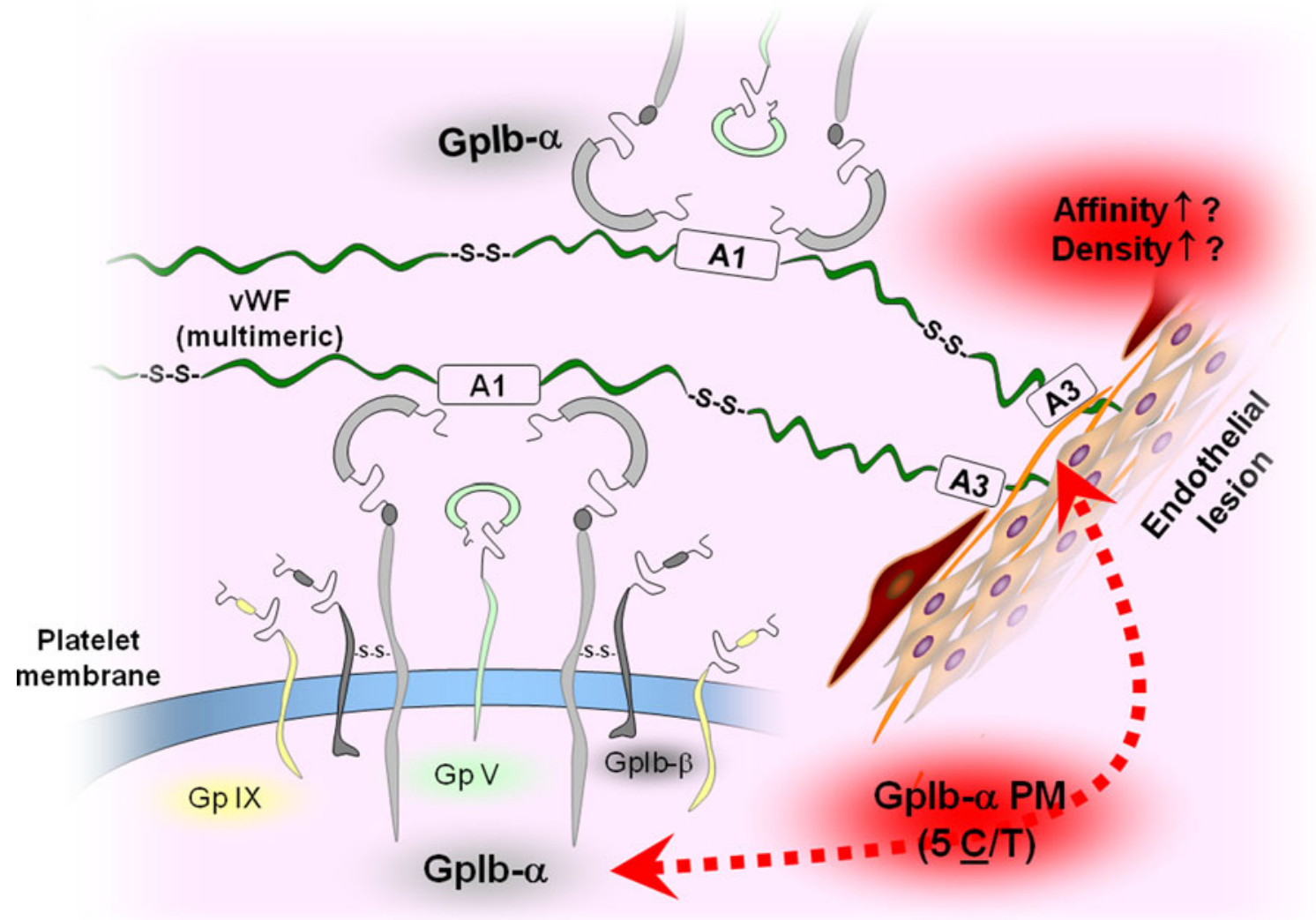

Fig. 1 Simplified overview of the interaction of GpIb-IX-V, von Willebrand Factor (vWF), and collagen. The GpIb-IX-V complex binds to the A1-binding site of vWF, while collagen, which may be exposed following endothelial injury, is bound to the A3 binding site of vWF. Gain-of-function mutation of the GpIb- $\alpha$ chain may influence both the binding of GpIb-IX-V complex to vWF, as well as the interaction of vWF with the (sub-) endothelium (e.g. via an increased density and/or affinity of the collagen binding site of vWF) downstream A3 domain to collagen [16], mutation of the $\mathrm{GPIb} \alpha$ gene may, furthermore, confer an increased thrombotic risk especially in conditions with high shear forces, as they occur in high-grade atherosclerotic lesions. This could explain a potential risk for adverse events in carriers of the GPIb $\alpha$ (5C) mutation and in those who smoke. Platelet binding to activated endothelium and/or collagen at damaged sites will not only translate into platelet plug formation but also to recruitment of monocytes (e.g. by exposed p-selectins) and acceleration of plaque formation and arterial stenosis [8], as may be the case in the CAVATAS population of smokers.

Contrary to our initial hypothesis, mutations in the PAR1 (IVSn-14), GPIa (807 C/T) and GPIIIa (HPA-1a/HPA1b) gene were not overrepresented in patients with symptomatic carotid artery stenosis as compared to controls, which was also true for the subgroup analyses (data not shown). Indeed, while earlier studies implied an association of SNP in the GPIa [31] or the GPIIIa [13, 32] gene with clinical events, more recent data speak against this hypothesis [33-35], which is in accord with our data. To our knowledge, our study is the first to investigate an association of the PAR-1 (IVSn-14) SNP with clinical events $[12,15]$. However, our data do not support a role of this SNP in the development of atherosclerotic carotid artery lesions.

In summary, our data show that none of the SNPs studied are overrepresented in a general cohort of patients with symptomatic carotid artery stenosis. Thus, their roles as single atherogenic risk factors in the general population remains to be determined. Although our findings are "negative" in this regard, they nevertheless appear to be important, since publication bias towards "positive" findings can severely skew the perception of polymorphisms associated with clinical events as demonstrated in a recent large-scale meta-analysis of polymorphisms in coronary artery disease [36]. On the other hand, our analysis of smokers revealed a significantly increased prevalence for the GPIb- $\alpha$ (5C) allele in this subgroup (despite a relatively low number of patients), which is in accord with and extends earlier studies. Our data, nevertheless, point towards a role of the GPIb- $\alpha$ (5C) allele as a synergistic 
"silent background risk factor", which is functional at high shear stress and potentiated by a typical exogenous risk resulting in accelerated atherosclerotic lesion formation. As such, these findings may have important implications for the carriers of this mutation, especially in the presence of the additional exogenous and hence modifiable risk factor, smoking.

One weakness of our study is that the calculated number of patients was not achieved due to limitations of the time frame for sample size collection. Nevertheless, even considering this small patient number, the study setting detected an overrepresentation of GPIb $\alpha$ in the subset of smokers. Given the exploratory nature of this study, our results should be viewed as hypothesis-generating. In view of the wealth of accumulating data, however, the synergy of arterial stenosis, high shear-favoured adhesionpolymorphism of GPIb $\alpha$ and smoking resulting in an increased platelet/endothelial reactivity deserves further exploration.

Acknowledgments The authors would like to thank Prof. Jürg Hüsler and Niki Zumbrunnen, University of Berne (Switzerland) for statistical analysis, Dr. Luca Pontiggia for technical support and Mrs Allison Dwileski for editing the manuscript. This work was supported by the Swiss National Foundation (Grant Nr. 32-59449.99 and 3200-068228.02 to J.H. Beer) and by the KARDIO Foundation Baden (to J.H. Beer), Switzerland. CAVATAS was funded by grants from the British Heart Foundation, the NHS Management Executive and the Stroke Association. The ultrasound laboratory at the central office was funded by the Wellcome Trust and the Neurosciences Research Foundation. MMB's Chair in Stroke Medicine at University College London is supported by the Reta Lila Weston Trust for Medical Research. Dr Lucy Coward and Ms Diane Thompson were responsible for patient recruitment and blood sampling, with support from Professor Graham Venables.

Conflict of interest The authors have no conflicts of interest to declare.

\section{References}

1. Ross R (1999) Atherosclerosis—an inflammatory disease. N Engl J Med 340:115-126

2. Beer JH, Pederiva S, Pontiggia L (2000) Genetics of platelet receptor single-nucleotide polymorphisms: clinical implications in thrombosis. Ann Med 32(1):10-14

3. Feinbloom D, Bauer KA (2005) Assessment of hemostatic risk factors in predicting arterial thrombotic events. Arterioscler Thromb Vasc Biol 25:2043-2053

4. Baker RI, Eikelboom J, Lofthouse E, Staples N, Afshar-Kharghan V, Lopez JA, Shen Y, Berndt MC, Hankey G (2001) Platelet glycoprotein Ibalpha Kozak polymorphism is associated with an increased risk of ischemic stroke. Blood 98:36-40

5. Meisel C, Afshar-Kharghan V, Cascorbi I, Laule M, Stangl V, Felix SB, Baumann G, Lopez JA, Roots I, Stangl K (2001) Role of Kozak sequence polymorphism of platelet glycoprotein Ibalpha as a risk factor for coronary artery disease and catheter interventions. J Am Coll Cardiol 38:1023-1027
6. Hsieh K, Funk M, Schillinger M, Endler G, Janisiw M, Reisinger $\mathrm{M}$, Unger $\mathrm{P}$, Greisenegger S, Lang W, Lalouschek W, Mannhalter C (2004) Vienna Stroke Registry Impact of the platelet glycoprotein Ib alpha Kozak polymorphism on the risk of ischemic cerebrovascular events: a case-control study. Blood Coagul Fibrinolysis 15:469-473

7. Frank MB, Reiner AP, Schwartz SM, Kumar PN, Pearce RM, Arbogast PG, Longstreth WT Jr, Rosendaal FR, Psaty BM, Siscovick DS (2001) The Kozak sequence polymorphism of platelet glycoprotein Ibalpha and risk of nonfatal myocardial infarction and nonfatal stroke in young women. Blood 97:875-879

8. Libby P (2002) Inflammation in atherosclerosis. Nature 420:868874

9. Seasholtz TM, Majumdar M, Kaplan DD, Brown JH (1999) Rho and Rho kinase mediate thrombin-stimulated vascular smooth muscle cell DNA synthesis and migration. Circ Res 84:11861193

10. Peng CY, Pan SL, Guh JH, Liu YN, Chang YL, Kuo SC, Lee FY, Teng CM (2004) The indazole derivative YD-3 inhibits thrombin-induced vascular smooth muscle cell proliferation and attenuates intimal thickening after balloon injury. Thromb Haemost 92:1232-1239

11. Nelken NA, Soifer SJ, O'Keefe J, Vu TK, Charo IF, Coughlin SR (1992) Thrombin receptor expression in normal and atherosclerotic human arteries. J Clin Invest 90:1614-1621

12. Dupont A, Fontana P, Bachelot-Loza C, Reny JL, Bieche I, Desvard F, Aiach M, Gaussem P (2003) An intronic polymorphism in the PAR-1 gene is associated with platelet receptor density and the response to SFLLRN. Blood 101:1833-1840

13. Pontiggia L, Lassila R, Pederiva S, Schmid HR, Burger M, Beer JH (2002) Increased platelet-collagen interaction associated with double homozygosity for receptor polymorphisms of platelet GPIa and GPIIIa. Arterioscler Thromb Vasc Biol 22:2093-2098

14. Douglas H, Michaelides K, Gorog DA, Durante-Mangoni E, Ahmed N, Davies GJ, Tuddenham EG (2002) Platelet membrane glycoprotein Ibalpha gene -5T/C Kozak sequence polymorphism as an independent risk factor for the occurrence of coronary thrombosis. Heart 87:70-74

15. Smith SM, Judge HM, Peters G, Armstrong M, Dupont A, Gaussem P, Storey RF (2005) PAR-1 genotype influences platelet aggregation and procoagulant responses in patients with coronary artery disease prior to and during clopidogrel therapy. Platelets $16: 340-345$

16. Andrews RK, Berndt MC (2004) Platelet physiology and thrombosis. Thromb Res 114:447-453

17. Pontiggia L, Steiner B, Ulrichts H, Deckmyn H, Forestier M, Beer JH (2006) Platelet microparticle formation and thrombin generation under high shear are effectively suppressed by a monoclonal antibody against GPIba. Thromb Haemost 96:774780

18. Forestier M, Resendiz JC, Pontiggia L, Lassila R, Beer JH (2008) Platelet microparticle suppressing antibody against GP Ibalpha acts independently of the filamin cleavage and increases protein tyrosine phosphorylation. Blood Coagul Fibrinolysis 19:801-806

19. Clemetson KJ, Clemetson JM (2008) Platelet GPIb complex as a target for anti-thrombotic drug development. Thromb Haemost 99:473-479

20. Maguire JM, Thakkinstian A, Sturm J, Levi C, Lincz L, Parsons M, Whyte S, Attia J (2008) Polymorphisms in platelet glycoprotein $1 \mathrm{~b}$ alpha and factor VII and risk of ischemic stroke: a meta-analysis. Stroke 39:1710-1716

21. Moshfegh K, Wuillemin WA, Redondo M, Lammle B, Beer JH, Liechti-Gallati S, Meyer BJ (1999) Association of two silent polymorphisms of platelet glycoprotein Ia/IIa receptor with risk of myocardial infarction: a case-control study. Lancet 353:351-354 
22. Oksala NK, Heikkinen M, Mikkelsson J, Pohjasvaara T, Kaste M, Erkinjuntti T, Karhunen PJ (2007) Smoking and the platelet fibrinogen receptor glycoprotein IIb/IIIA PlA1/A2 polymorphism interact in the risk of lacunar stroke and midterm survival. Stroke 38:50-55

23. Endovascular versus surgical treatment in patients with carotid stenosis in the Carotid and Vertebral Artery Transluminal Angioplasty Study (CAVATAS): a randomised trial (2001). Lancet 357:1729-1737

24. Dichgans M, Markus HS (2005) Genetic association studies in stroke: methodological issues and proposed standard criteria. Stroke 36:2027-2031

25. Kopp Lugli A, Brown M, Buechi L, Foerznler D, Spleiss O, Dupont A, Gaussem P, Forestier M, Beer JH (2007) Frequency of the homozygous PAR-1 (IVS-14T/T) receptor polymorphism in the CAVATAS population of patients with severe carotid stenosis. Forum Med Suisse, Suppl 35:165

26. Germer S, Holland MJ, Higuchi R (2000) High-throughput SNP allele-frequency determination in pooled DNA samples by kinetic PCR. Genome Res 10:258-266

27. Kunicki TJ, Kritzik M, Annis DS, Nugent DJ (1997) Hereditary variation in platelet integrin alpha 2 beta 1 density is associated with two silent polymorphisms in the alpha 2 gene coding sequence. Blood 89:1939-1943

28. Kocsis I, Vasarhelyi B, Gyorffy A, Gyorffy B (2004) Reanalysis of genotype distributions published in "Neurology" between 1999 and 2002. Neurology 63:357-358

29. Afshar-Kharghan V, Li CQ, Khoshnevis-Asl M, Lopez JA (1999) Kozak sequence polymorphism of the glycoprotein (GP) Ibalpha gene is a major determinant of the plasma membrane levels of the platelet GP Ib-IX-V complex. Blood 94:186-191
30. Cadroy Y, Sakariassen KS, Charlet JP, Thalamas C, Boneu B, Sie P (2001) Role of 4 platelet membrane glycoprotein polymorphisms on experimental arterial thrombus formation in men. Blood 98:3159-3161

31. Antoniades C, Tousoulis D, Vasiliadou C, Stefanadi E, Marinou K, Stefanadis C (2006) Genetic polymorphisms of platelet glycoprotein Ia and the risk for premature myocardial infarction: effects on the release of sCD40L during the acute phase of premature myocardial infarction. J Am Coll Cardiol 47:1959-1966

32. Weiss EJ, Bray PF, Tayback M, Schulman SP, Kickler TS, Becker LC, Weiss JL, Gerstenblith G, Goldschmidt-Clermont PJ (1996) A polymorphism of a platelet glycoprotein receptor as an inherited risk factor for coronary thrombosis. N Engl J Med 334:1090-1094

33. Nikolopoulos GK, Tsantes AE, Bagos PG, Travlou A, Vaiopoulos G (2007) Integrin, alpha 2 gene C807T polymorphism and risk of ischemic stroke: a meta-analysis. Thromb Res 119:501-510

34. Ridker PM, Hennekens CH, Schmitz C, Stampfer MJ, Lindpaintner K (1997) PIA1/A2 polymorphism of platelet glycoprotein IIIa and risks of myocardial infarction, stroke, and venous thrombosis. Lancet 349:385-388

35. Wiwanitkit V (2006) PIA1/A2 polymorphism of the platelet glycoprotein receptor IIb/IIIIa and its correlation with myocardial infarction: an appraisal. Clin Appl Thromb Hemost 12:93-95

36. Ye Z, Liu EH, Higgins JP, Keavney BD, Lowe GD, Collins R, Danesh J (2006) Seven haemostatic gene polymorphisms in coronary disease: meta-analysis of 66,155 cases and 91,307 controls. Lancet 367:651-658 